\title{
12 Appropriate staff and student relationships policy
}

\author{
Nicholas Gamble and Christopher Boyle
}

\section{How to use this policy}

The relationship between school staff and students is very important. It has the potential to impact on the wellbeing, academic progress and sense of belonging for students and job satisfaction and retention of school staff. However, despite being a rare occurrence, recent coverage around the world has also shown that school settings have been implicated in the abuse of young people. Therefore, in order to protect both school staff and students, a clear policy on the interactions and social relationships between school staff and students is needed.

It is important to be aware that there are legislative requirements in many jurisdictions that place limits on interactions and require school staff to refrain from some interactions with students. The implementation of this policy must set expected behaviours and interactions above these mandated levels. There will also be specific professions working in schools such as psychologists, counsellors and social workers who may have legal and ethical obligations that exceed other school staff (Australian Psychological Society, 2007; Boyle \& Gamble, 2014; Psychotherapy and Counselling Federation of Australia, 2017). The obligations for these staff may even preclude them from attending some school gatherings.

School leaders should implement polices around interactions and relationships with students that set out to maintain and promote positive relationships but also to protect students and staff from inappropriate relationships. School leaders will need to consider legislative and policy requirements in their jurisdiction and professional requirements of staff in developing this policy.

[To adapt and use this policy, delete or modify the text as indicated]

\section{[INSERT name of school] Appropriate staff and student relationships policy}

\section{Rationale}

There is an underlying power differential between school students and school staff (Richmond \& McCroskey, 1984; Schrodt et al., 2007). It is important for 
school staff of all types to be aware of their influence and position of trust and power. This position of power can impact relationships between staff and students. Although the differential may be more obvious in the interactions between teaching staff and students in that these members of staff will grade work and communicate with parents, it is present in all relationships between school staff and students. All school staff have a position of power and influence that is explicitly or indirectly felt by the student body (Allan \& I'Anson, 2004). It is important that all school staff are mindful of this differential in relationships when they interact with students.

There is discussion in the academic literature about the importance of developing relationships between teaching staff and students in the school setting (Bernstein-Yamashiro \& Noam, 2013) and digital environments (Asterhan \& Rosenberg, 2015). With the rise of social media platforms, there has been a focus on interactions between staff and students on these platforms. The findings in relation to academic achievement and engagement have been mixed with much of the discrepancy said to come from how the tools are used (e.g., Dohn \& Dohn, 2017; Lu et al., 2016; Matzat \& Vrieling, 2016). However, there are also reports of social relationships developing between staff and students that have led to sexual and physical abuse (e.g., Moulden et al., 2010; Steely \& Ten Bensel, 2019). Therefore, it is critical for school leaders to have a clear policy for school staff in relation to interactions and relationships in both the physical and online environments.

\section{Purpose}

The purpose of this policy is to outline the shared responsibility of students, parents and guardians, and school staff in engaging in appropriate interactions and relationships. It is vital for all members of the school community to engage in interactions, behaviours and relationships that foster professional interactions between school staff and students. These include nurturing and mentoring relationships when professional roles require it. However, personal or social relationships and/or interactions should not occur between staff and students in online or in person settings.

\section{Scope}

This policy applies to current and past students, teachers, staff, school leaders and parents of [INSERT name of school]. A whole school approach to appropriate relationships is needed and this is the responsibility of the school community.

[INSERT specific roles and responsibilities of individuals or teams] 


\section{Policy statement}

[INSERT name of school] requires staff to interact in an appropriate professional manner with students, parents, and former parents and students. Staff members within the school hold a position of power and influence and must be mindful of this differential in their interactions.

The underlying expectation of all staff at [INSERT name of school] is that their interactions and relationships with all students and parents foster a positive learning environment within a caring, supportive and inclusive school environment (Zollers et al., 1999).

[INSERT name of school] staff must only engage in professional relationships with their students, even if other types of relationships are initiated by the student. Staff should also be mindful of how relationships may be perceived by others (Department of Education United Kingdom [DEUK], 2011; NSW Department of Education and Communities [NDEC], 2014; Victorian Institute of Teaching [VIT], n.d.).

Due to their inherently risky nature, [INSERT name of school] recommends that school staff do not follow or accept friend requests from students or parents on social media, socialise with students at gatherings outside of school or see any given student in informal settings when providing support (e.g., at your house) (NDEC, 2014). In the very rare circumstances when these might be deemed appropriate, parental consent and approval from the head of [INSERT name of school] are required.

The staff of [INSERT name of school] understand that professional relationships with students and parents are based on mutual respect (Hallinan, 2008; Queensland College of Teachers, n.d.).

Staff at [INSERT name of school] understand the dynamic nature of diversity in the students and families enrolled at the school and respond in a positive and responsive way to the unique attribute of each child (National Education Association [NEA], 2010; Villegas \& Lucas, 2002; VIT, n.d.).

There is a progressive correlation between positive and supporting professional relationships (den Brok et al., 2004; Dohn \& Dohn, 2017). Staff at [INSERT name of school] engage in supportive and child-focused professional relationships with students and parents.

Given their influence, [INSERT name of school] reminds staff to be extremely conscious of the nature of comments and jokes to ensure that they are free of prejudice in those areas covered by anti-discrimination or other similar legislation in their jurisdiction. However, beyond this, it is essential to ensure that students and/or parents do not feel embarrassed or disrespected by staff comments (DEUK, 2011; NEA, 2010).

\section{Online relationships}

[INSERT name of school] does/does not allow staff to communicate via social media with students and/or parents regarding school business. 
[INSERT name of school] does/does not allow staff to communicate via text messaging with students and/or parents regarding school business.

[INSERT name of school] permits the use of social media to communicate with a student for the strict purpose(s) of [List specific approved uses of social media in school]. These interactions should only take place if the staff member has a dedicated social media profile for professional purposes (Muñoz \& Towner, 2011).

[INSERT name of school] permits the use of text messages to communicate with students for the strict purpose(s) of [List specific approved uses of social media in school].

[INSERT name of school] is mindful that school staff's presumed private conduct on social media sites may be publicly shared with students and parents. Staff are reminded to be conscious of maintaining an appropriate demeanour even in private online spaces and that no details about students or parents are to be posted online (O'Connor \& Schmidt, 2015).

\title{
Parents and families
}

[INSERT name of school] does not recommend developing social relationships with parents and/or older siblings of current students as it can lead to a conflict of interest and can further increase the influence and power of the staff member. If there are pre-existing relationships, care should be taken to minimise any negative impact on the student (Australian Psychological Society, 2016; NDEC, 2014).

Although it is important to consider the age of the child and the context, [INSERT name of school] school staff should be cautious giving or receiving gifts from students. The cost, occasion and motivation of the gift should be considered. Gifts that facilitate or encourage social connections to be established outside of the professional relationship are not to be exchanged (NEA, 2010; NDEC, 2014; Wang, 2008).

\section{Authorship}

Dr Nicholas Gamble, Monash University

Associate Professor Christopher Boyle, University of Exeter

[INSERT RELEVANT STAFF MEMBERS]

\section{Related Policy and Documents}

\author{
[INSERT RELEVANT POLICY AND DOCUMENTS] \\ Inclusion policy \\ Wellbeing policy \\ Safety policy \\ Counselling policy \\ Anti-bullying and discrimination policy
}




\section{Rating of evidence base}

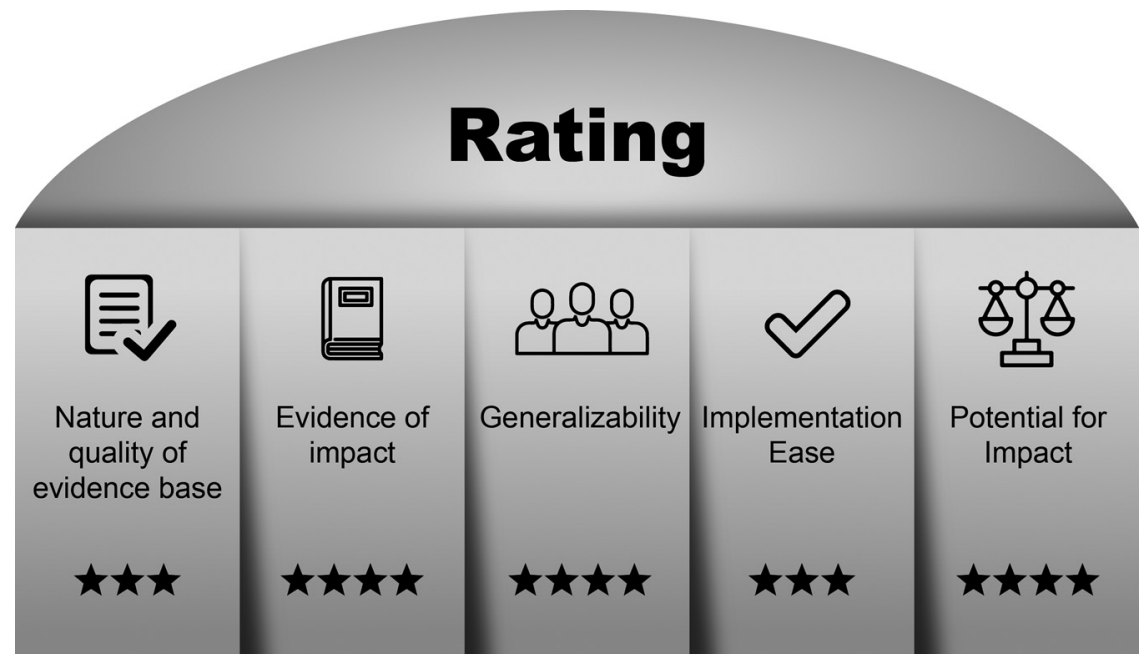

Figure 12.1. Appropriate Staff and Student Relationships Rating of Evidence.

Author Note. For many aspects of this policy, direct research is limited as school staff engaging in relationships outside of those detailed here are in breach of their legal, professional and ethical obligations. Therefore, it is difficult to empirically investigate some of these issues. For this reason, a mixture of empirical research that supports the appropriate behaviours and policy documents from international regulatory bodies was used to develop this policy. There is strong evidence that school staff who reflect on and monitor their interactions with students and parents face a lower risk of developing inappropriate relationships. As the majority of these issues covered relate to ethically appropriate behaviour, the policy documents for a range of international jurisdictions were evaluated for consistency. It does require teachers to consider and adapt their behaviour (especially in online contexts) but not unreasonably so. If school staff limit their behaviour and engage as described, the potential for problematic relationships developing will be substantially reduced.

\section{Date of ratification}

This policy was ratified on the [INSERT DATE].

\section{Date of review}

This policy will be reviewed by [INSERT DATE].

\section{References}

Allan, J., \&, I'Anson, J. (2004). Children's rights in school: Power, assemblies and assemblages. The International Journal of Children's Rights, 12(2), 123-138. 
Asterhan, C. S., \& Rosenberg, H. (2015). The promise, reality and dilemmas of secondary school teacher-student interactions in Facebook: The teacher perspective. Computers \& Education, 85, 134-148.

Australian Psychological Society. (2007). Code of Ethics. Australian Psychological Society.

Australian Psychological Society. (2016). Ethical guidelines for managing professional boundaries and multiple relationships. Australian Psychological Society.

Bernstein-Yamashiro, B., \& Noam, G. G. (2013), Teacher-student relationships: A growing field of study. New Directions for Youth Development, 2013(137), 15-26.

Boyle. C., \& Gamble, N. (2014). Ethical practice in applied psychology. Oxford University Press.

den Brok, P. Brekelmans, M., \& Wubbels, T. (2004). Interpersonal teacher behaviour and student outcomes. School Effectiveness and School Improvement 15(3-4), 407-442.

Dohn, N. B., \& Dohn, N. B. (2017). Integrating Facebook in upper secondary biology instruction: a case study of students' situational interest and participation in learning communication. Research in Science Education, 47(6), 1305-1329.

Department of Education United Kingdom [DEUK]. (2011). Teacher standards. https:// assets.publishing.service.gov.uk/government/uploads/system/uploads/attachment_data/ file/665520/Teachers__Standards.pdf

Hallinan, M. T. (2008). Teacher Influences on students' attachment to school. Sociology of Education, 81(3), 271-283.

Lu, J., Hao, Q., \& Jing, M. (2016). Consuming, sharing, and creating content: How young students use new social media in and outside school. Computers in Human Behavior, 64, 55-64.

Matzat, U., \& Vrieling, E. M. (2016). Self-regulated learning and social media - a "natural alliance"? Evidence on students' self-regulation of learning, social media use, and student-teacher relationship. Learning, Media and Technology, 41(1), 73-99

Moulden, H. M., Firestone, P., Kingston, D. A., \& Wexler, A. W., (2010) A description of sexual offending committed by Canadian teachers. Journal of Child Sexual Abuse, 19(4), 403-418.

Muñoz, C. L., \& Towner, T. (2011). Back to the "wall": How to use Facebook in the college classroom. First Monday, 16(12). https://firstmonday.org/ojs/index.php/fm/ article/view/3513/3116

National Education Association [NEA]. (2010). Code of ethics [Amended]. https://www. nea.org/assets/docs/Code_of_Ethics_Education_Profession_NEA_HB_2019.pdf

NSW Department of Education and Communities [NDEC]. (2014). Code of conduct. https://www.teach.nsw.edu.au/documents/code_guide.pdf

O'Connor, K. W., \& Schmidt, G. B. (2015). "Facebook Fired": Legal standards for social media-based terminations of K-12 public school teachers. SAGE Open, 5(1).

Psychotherapy and Counselling Federation of Australia. (2017). PACFA code of ethics. https://www.pacfa.org.au/wp-content/uploads/2020/09/PACFA-Code-ofEthics-2017.pdf

Queensland College of Teachers. (n.d.). Code of ethics for teachers in Queensland. https:// cdn.qct.edu.au/pdf/CodeOfEthicsPoster20081215.pdf?_ga=2.144941620.1269174387. 1585371776-1852286359.1585371776

Richmond, V. P., \& McCroskey, J. C. (1984). Power in the classroom II: Power and learning. Communication Education, 33(2) 125-136. 


\section{Gamble \& Boyle}

Schrodt, P., Witt, P. L., \&. Turman, P. D. (2007). Reconsidering the measurement of teacher Power Use in the College Classroom. Communication Education, 56(3), 308-322.

Steely, M., \& Ten Bensel, T. (2019). Child sexual abuse within educational settings: A qualitative study on female teachers who sexually abuse their students. Deviant Behavior, 41(11), 1440-1453.

Victorian Institute of Teaching [VIT]. (n.d.). The Victorian teaching profession code of conduct. https://www.vit.vic.edu.au/_data/assets/pdf_file/0018/35604/Code-ofConduct-2016.pdf

Villegas, A. M., \& Lucas, T. (2002). Preparing culturally responsive teachers: Rethinking the Curriculum. Journal of Teacher Education, 53(1), 20-32.

Wang, D. (2008). Family-school relations as social capital: Chinese parents in the United States. School Community Journal, 18(2), 119-146.

Zollers, N. J., Ramanathan, A. K., \& Yu, M. (1999). The relationship between school culture and inclusion: How an inclusive culture supports inclusive education. International Journal of Qualitative Studies in Education, 12(2), 157-174. 